\title{
La formación de la subjetividad en los espacios cotidianos ${ }^{1}$
}

\author{
The formation of subjectivity in everyday spaces ${ }^{1}$
}

\author{
Clara Inés Giraldo Naranjo*
}

\section{Resumen:}

El presente artículo tiene como objetivo conceptualizar la noción formación de subjetividad. En las siguientes líneas se considera este aspecto y la configuración de dicha categoría. Se partede los planteamientos de Berger, Luckmann, Vargas Guillén, Mijaíl Bajtín y Schütz. Se continúa este trayecto con la visión fenomenológica; de otro lado, se analizará el papel de la formación frente a la constitución del sujeto y, finalmente, se busca dilucidar las transformaciones que ha ido configurando esta temática desde nuestra realidad actual.

Palabras clave: Socialización primaria; Socialización secundaria; Lenguaje; Polifonía, Fenomenología; Constitución; Formación; Subjetividad.

Candidata a Magíster en Educación y Desarrollo Humano, Universidad de Manizales en convenio con el CINDE, Profesional de la Fundación Saldarriaga Concha. claragiraldo2I@hotmail.com

Sánchez, A. M., Molina, A. M., Giraldo, C. I, Escobar, G. J., Artículo de la Investigación: "La vida familiar como experiencia subjetiva". Tesis de maestría no publicada para optar al título de magíster en Educación y Desarrollo Humano, convenio CINDE-Universidad de Manizales, Manizales, 2010. 
Tea Clara Inés Giraldo Naranjo

\section{Abstract}

This article aims to conceptualize the notion of subjectivity formation. In the following lines is considered this aspect and the settings for that category. Be part of the approach of Berger, Luckmann, Guillen Vargas, Mijail Bajtín and Schütz. We continue this journey with the phenomenological view, on the other hand, will analyze the role of training against the constitution of the subject and, finally, we seek to elucidate the changes that have taken shape this issue from our current reality.

Keywords: Primary socialization; Secondary socialization; Language; Polyphony; Phenomenology; Formation; Subjectivity.

Para iniciar este escrito se parte de una pregunta orientadora que tendrá la función de dirigir y concatenar los planteamientos que se expondrán: ¿cuál es el papel del sujeto en la formación de la subjetividad? La respuesta a este cuestionamiento remite a momentosde la socialización primaria, que se llevan a cabo desde el contexto familiar que rodea la historia de desarrollode cada individuo y, en definitiva, es en estos escenarios en los que se construyen historias y experienciascon el poder de moldear y marcar la esencia de cada ser humano.

Este espacio de construcción tiene un carácter impositivo porque asume que los niños enfrentanun mundo ya constituido que los trasciende y los define. En esta etapa se presentan significantes, referentes y vivencias experienciales que constituyen la realidad objetiva. "Partiendo del nexo afectivo que impera en este momento de la vida, el niño logra identificarse con los otros significados que circulan en esta socialización, lo que hace que los resultados de este momento de la vida queden fuertemente arraigados y registradosen la conciencia subjetiva de los niños", tal como lo refieren Berger y Luckman (2001, p. 15 ).

Hablamos de experiencias familiares vividas y experimentadas por cada uno de nosotros, muchas veces sin tener la plena conciencia de la carga afectiva que tienen y del significado que poseen porque marcan lo que hemos sido, lo que somos y lo que seremos. La vida familiar es el espacio por excelencia para la configuración de lo humano: allí suceden la construcción y constitución del sujeto. En este sentido, la forma como las familias se componen, identifican y distinguen, y las percepciones que cada uno de los integrantes tiene frente a las experiencias vividas en familia son visibles en la manera como ese sujeto piensa, interactúa, interpreta, narra sus experiencias y se proyecta en su medio. Esto exige una comprensión del momento histórico que vive la familia y, con ello, la necesidad de orientar los procesos de esas vivencias para que se conviertan en espacios de indagación, reflexión e interpretación y rescatar así, el rol formativo de la familia.

De otro lado, es importante señalar que los momentos de socialización secundaria se desarrollan en contextos de interacciones humanas, diferentes al familiar; y es en esas nuevas vivencias construidas en los barrios, los jardines infantiles, las instituciones educativas y los espacios de encuentro con otras personas donde son entabladas nuevas relaciones y circulan otros significados y otros intereses e historias de vida que muchas veces nos trascienden y definen. Con respecto a la de socialización, es importante resaltar que es en la socialización secundaria donde cada 
sujeto, en un acto consciente, puede generar rupturas, cortes y modificaciones de lo aprendido en otros momentos de la historia de la vida, a partir de la reinterpretación y reorientación de hechos y situaciones de la vida misma desde un acto reflexivo, intuitivo y develador.

Definitivamente, en los primeros momentos de nuestra vida éramos simplemente como esponjas que todo lo recibíamos sin oponer resistencia, sin realizar acciones selectivas frente a lo que deseábamos incorporar en nuestras estructuras mentales y en nuestras propias almas y, como es de suponer, todas estas prácticas tempranas se conjugaron $\mathrm{y}$ nos constituyen, desde lo más profundo de nuestro ser que definen nuestra identidad, nuestra manera de pararnos en un mundo objetivo, asumiendo un rol determinado en el espacio inmediato en el que nos encontramos inmersos. Pero es precisamente, a partir de estas reflexiones, como cada sujeto puede analizar su mismidad y puede reescribir experiencias e historias que le permitan sentirse y ser diferente, develando sus actuaciones de acuerdo con sus deseos propios.

Schütz y Luckmannplantean al respecto: "es precisamente en el mundo de la vida cotidiana donde se construyen los significados; un mundo considerado hasta entonces como un espacio de lo irrelevante, de lo repetitivo, donde ocurren nuestras acciones de manera 'inconsciente”" (Schutz, 1973, p. 93).

La actitud natural de la mayoría de los sujetos se caracteriza por el supuesto de que el mundo de la vida que yo acepto como dado es también aceptado como dado por mis semejantes, y, como es de suponer, todos entramos en un juego en el que las jugadas no deben sorprender; todos hacemos parte de una línea imaginaria que lleva trazado un camino predeterminado, formado por nuestras actuaciones y participaciones en el mundo objetivo.

A partir del aporte de estos autores, como valdría la pena develar, que además de ser los receptores pasivos de todas estas informaciones decodificadas e incorporadas en nuestra conciencia, también tenemos la posibilidad de ser una síntesis activa y pensante que nos invita a tener palabras, argumentos $y$ voz propia, para comprender lo que hemos configurado desde nuestra existencia, sobre todo cuando asumimos una actitud consciente y autocrítica de lo que somos y de lo que en realidad queremos ser. En este sentido, será nuestra conciencia abierta y flexible en la vida la que nos posibilitará generar rupturas con lo aprendido, tendientes a posibilitar espacios donde seamos protagonistas activos en la construcción de nuestra realidad.

Por su parte, Schütz (1973) "sostiene que el individuo tiene capacidad de actuar en el mundo preorganizado" (p. 34). Partiendo de este postulado surge una pregunta ¿cómo puede el individuo transformar el mundo? La respuesta más clara es que el individuo puede modificar el mundo preorganizado como actor social, como protagonista activo y reflexivo que abandona los actos rutinarios cuando se ve enfrentado a problemas,fines, convicciones y nuevos retos.

Los planteamientos expuestos muestran un camino, una dirección que indica que el sujeto esformado porlas experiencias y circunstancias vividas desde sus entornos cotidianos; por los sentidos y los sentires que circulan en el mundo dellenguaje y son estos los que dejan una huella 
indeleble en la conciencia; pero, también, este mismo sujeto puede ejercer un rol activo frente a su propia reconfiguración, cuando genere un acto reorientador que le permita mirarse, sentirse, reconocerse, comprenderse, vivirse, entretejerse y valorar lo que ha sido, lo que es y lo que en realidad quiere ser.

El lenguaje, es el que marca las coordenadas y el horizonte de la vida en sociedad parallenar esa vida de objetos, de sentidos y de significados. Conozco, simbolizo y nombro la realidad objetivaasumiéndolay haciendo partede ella; $y$ complementa Rizo (2005, p. 20), el lenguaje es subjetivo y construido en sociedad.

A partir del lenguaje como estructura lingüística innata, somos esencialmente polifonía, entendida como la pluralidad de las voces, de todo lo que fue comprendido, escuchado, percibido, experimentado, sentido, transmitido y expresado a lo largo de nuestra existencia por todas aquellas personas que han hecho parte de la misma y que, tal vez sin pensarlo, trazaron una línea para que cada uno de nosotros transite.

Vargas Guillén retoma la expresión "polifonía de voces" (2007) y señalaque corresponde a una voz recibida por todos los escuchados según su propio horizonte de experiencia. Una misma voz —en la mesa familiar, en el aula o que resulta impresa- es recibida y asumida por todos y cada uno de los interlocutores desde su perspectiva; pero también es importante no dejarla pasar por alto como una voz en medio de otras tantas para las que se han tenido oídos. Una voz se hace más significativa, poderosa y valiosa, $\mathrm{y}$ es la más escuchada y vivificada en medio de muchas otras que contribuyen a laformación del sentido del mundo. El autor señala que hay voces que han tenido un mayor eco, una mayor resonancia y una mayor fuerza y trascendencia en la definición de lo que somos, de nuestra personalidad, en la formación de nuestra subjetividad.

¿Podrá generalizarse este planteamiento de Vargas Guillén y podría aceptarse una verdad que señala que en nuestras vidas han existido voces, expresiones e imágenes con más poder que otras? Este es un buen interrogante, es, ante todo, un cuestionamiento que nos invita a develar en nuestras actuaciones y discursos la perpetuación de otros, de aquellos congéneres, predecesores y antecesores que han hecho parte de nuestra vida cotidiana, del entramado de significados que nos definen; seres con el poder de estar presentes en el aquí y en el ahora, y que, aun en el caso de no estar físicamente, siguen presentes y constantes en nuestro accionar y en las características que nos acompañan y nos diferencian de los demás. Vargas Guillén también refiere que para la elección personal, todas y cada una de las voces son tan solo insinuaciones. Al cabo, es uno mismo el que decidirá con mayor o menor grado de comprensión (crítica) hacer suyas unas voces que explican, justifican o sustentan la determinación propia.

Por su parte Mijaíl Bajtín (1982) emplea el término 'polifonía' para referirse a la pluralidad de voces que corresponden a múltiples conciencias. Rechaza la concepción de un yo individualista: el yo es esencialmente social. Cada individuo seconstituye como un colectivo de numerosos yoes que ha asimilado a lo largo de su vida, en contacto con las voces escuchadas que conformannuestra manera de pararnos en el mundo.

Tanto Vargas Guillén (2007) como Bajtín 
(1982), logran puntos de encuentro desde sus planteamientos cuando aluden a la influencia de la polifonía de las voces escuchadas por los predecesores en la definición de lo que somos. Las actuaciones y desempeños y nuestra manera de proceder en el mundo de la vida son el resultado y la consecuencia de todas esas voces, informaciones, sentidos y significados transmitidos en diferentes momentos; igualmente, es importante señalar el valor y la fuerza que cobra la posibilidad de que el sujeto sea un activo participante en su formación, cuando evalúa cuáles son las voces que lo han reconfigurado y cuáles son, en realidad, las que él desea que sigan presentes en su proceder y en sus actuaciones.

Schütz (1973) plantea:

La experiencia del otro es estructura según esté referida a un mundo de asociados o congéneres (personas con las que existe una experienciainmediata, pues han hecho parte de nuestro mundo, $y$ con ellas se establecen relaciones cara a cara); a un mundo de contemporáneos (personas de las cuales se sabe que existen en el mismo tiempo en que vivimos, perodelascualesnohayexperiencia inmediata, y que están por fuera del contexto situacional del sujeto); y a un mundo de antecesores y a un mundo de sucesores. Las acciones referidas a los asociadosse guían por una orientación tú o por una relación nosotros, mientrasquelasaccionesreferidasa loscontemporáneos, antecesoresysucesores, son guiadas por una orientación ellos y una relación ellos (p. 25).

Tal como lo enuncia Schütz (1973) "existe un mundo experiencial, unos espacios cotidianos donde no estamos solos, donde nos conectamos, nos acercamos y habitamos con otros individuos que son portadores de significados y con quienes establecemos vínculos, encuentros, desencuentros, relaciones simbióticas" (p. 25). Ahora bien, vale la pena preguntarnos, crítica e introspectivamente, quiénes son esas personas, esos congéneres, contemporáneos, antecesores y sucesores citados por Schütz y Luckmann (1973), que, aun con el paso del tiempo, siguen presentes en nuestras acciones, acompañando nuestras actuaciones y desempeños existenciales: serán nuestros padres, familiares, amigos, enemigos $y$ docentes los que siguen dirigiendo nuestro accionar en el mundo, sin darnos la oportunidad de generar cortes y rupturas con modelos de formación aprendidos e incorporados.

Es preciso devolvernos a la pregunta que originó este artículo: ¿cuál es el papel del sujeto en la formación de la subjetividad? Definitivamente, hay algo que empieza a quedar claro desde el desenlace de este escrito, y es que el papel del sujeto frente a la edificación de su mismidad no es pasivo; no basta con que reconozca que él puede ser una síntesis activa de la información de otros, de aquellos predecesores; no es suficiente el discernimiento frente a la influencia de la polifonía de voces escuchadas a lo largo de la vida, en la definición de lo que se es. Se torna necesario un sujeto con la capacidad e iniciativa de ir más allá y de ser protagonista activo en la construcción de su realidad personal. Un ser humano capaz de volverse a él mismo, desde un acto reflexivo y propio que le permita evaluar y discernir críticamente las experiencias, percepciones, imágenes, actitudes e informaciones recibidas que han orientado su manera de actuar y de parase en una realidad habitada por otros seres humanos. Es así como este mismo sujeto puede tomar decisiones y definir acciones de cambio frente a lo que el desea ser, teniendo también la posibilidad de establecer 
y desencadenar recursos de logro personales para reinterpretar aspectos de su vida con los que no quiere seguir conviviendo.

Desde el punto de vista fenomenológico, Schütz (1974) asevera que el sentido de mundo y de nuestro yo en él mismo no se da pasivamente; ya está allí presente, cuando ponemos en acción cualquier noción, ya la poseemos; ya se nos ha dado previamente. $\mathrm{La}$ realidad de la vida se presenta ya objetivada, es decir, constituida y definida por un orden de objetos que han sido designados como objetos antes de que yo apareciera en escena.

La fenomenología de lo sobreentendido parte de lo que pasivamente se da; la comprensión intersubjetiva está dada por lo común, como lo expone Gadamer: aceptación, rechazo, transformación, modificación de una voz (popular,cultural,personal,familiar,ciudadana, nacional; de la época, histórica) que se haya escuchado y que compartan los miembros de unmismoentorno(horizontepopular,cultural, personal,familiar,contextosituacional,etc.).En este orden de ideas, vale la pena analizar el papel de la formación frente a la configuración del sujeto.

\section{¿Cómo se forman sujetos y colectivos?}

Es aceptable la comparación que señala a los sujetos cuando entran a un partido que ya está jugado y puesto en escena, como se señala desde la fenomenología. Desde este escenario debemos llegar no solo a reconocer a los otros jugadores y participantes; también debemos saber cómo acceder al campo, a la bola, a las reglas del juego; todos estos aspectos forman parte del mundo objetivo.

En otro momento, se alcanzará un estado de autoreconocimiento, que puede denominarse como el momento fenomenológicoo trascendental de la constitución de la subjetividad. Desde este proceso para el sujeto, el mundo y los otros llegan a tener sentido porque unos y otros se le presentan a uno como sujeto; porque pueden operar el sentido en ese mundo, porque a lo encontrado se le asigna valor o validez desde su posición como sujeto en primera persona.

La formación, en este sentido, requiere el reconocimiento del carácter constitutivo del ser humano, de la cultura, en la que el mundo se le presenta pasivamente al sujeto; pero, igualmente, se reconoce el valor de conferir un puesto de privilegio a la persona que hace el sentido, la vida, la construcción, la autodirección, la pluralidad de perspectivas en la búsqueda de potenciarse como sí mismo y encontrar su esencia, Vargas (2007).

El problema de la formación se origina en lo que implica la categoría "ser uno mismo", lo que connota hacer valer el punto de vista propio, jugar el partido en primera persona y potenciar la expresión del sí mismo. Es un asunto que definitivamente requiere de una actitud fundamental enmarcada en la capacidad del sujeto para pararse desde el mundo de la vida, como ser humano pensante, reconociendo su mismidad, su alteridad, sus posibilidades de participar en las jugadas y de ser un protagonista real.

A partir de los planteamientos expuestos, se entiende la formación como el desarrollo particular del sí mismo, lo que implica tener en cuenta los siguientes aspectos:

- ¿Cuál ha sido el papel de las experiencias, vivencias y prácticas cotidianas presentes 
en lasocialización primaria y secundaria expuesta por Berger y Luckmann frente ala formación particular del sí mismo?

- ¿Por qué la polifonía de voces escuchadas en otros momentos de la vida del sujeto siguen presentes en su accionar? ¿Será necesario generar cortes con lo aprendido para alcanzar a ser protagonistas de nuestras vivencias?

- ¿Cuál es la influencia de los predecesores, congéneres y contemporáneos frente a la definición de lo que somos, y hasta qué punto se requiere modificar esquemas aprendidos en momentos pasados de nuestra vida para alcanzar un verdadero despliegue del yo particular?

De acuerdo con los planteamientos expuestos, podríamos decir que la subjetividad es el resultado de la constitución de un sujeto; es una construcción de lo personal y lo social a partir de la interacción con otros en un entorno determinado. En la subjetividad convergen las percepciones, sentimientos, argumentos, prejuicios, lenguajes, actitudes, memorias, sensaciones e imágenes que nos acompañan y que definen nuestras actuaciones. La subjetividad se define como el resultado del encuentro de los impulsos primitivos del ser humano con las exigencias de su entorno social predeterminado. Hablar de subjetividad es hablar de la condición de los sujetos, de su índole, de sus peculiaridades, de su naturaleza, de aquello que los delimita y distingue del mundo de los objetos, Ruiz (1988).

El mundo dado tiene que ser sometido a evaluaciones por parte de la persona hasta llegar a formar su propia autoimagen desde su voz propia, desde su yo interior. En este sentido, se podría responder la pregunta que originó el presente escrito y expresar que, en definitiva, el sujeto puede cumplir un rol activo y determinante frente a la construcción de su subjetividad. Son innegables las influencias del entorno circundante frente a lo que es cada ser humano, pero también sería inaceptable no reconocer el papel que puede y debe desempañar cada persona para asumir posición frente a su realidad y a lo vivido. Es en este punto donde entra el ámbito de la reflexión con total independencia para llegar a la autodefinición y autodeterminación; en otras palabras, ser el mismo y contribuir a la construcción del mundo. De esta manera, el sujeto es formado por el mundo, pero igualmente es innegable el planteamiento que refiere que el mundo es formado por el sujeto: existe una relación bidireccional, enuncia Vargas (2007).

También es menester hacer referencia a los cambios culturales, políticos, tecnológicos y sociales del momento. Hoy han surgido nuevas dinámicas sociales que afectan nuestra manera de percibir las situaciones $\mathrm{y}$ acontecimientos que configurannuestra subjetividad. Estas transformaciones han generado nuevos contextos en los que los sujetos han tenido que enfrentarse a otros sucesos que les exigen respuestas diferentes.

Todo este entramado, entrelazado por nuevas formas de significar la realidad, ha generado transformaciones profundas en el ámbito subjetivo, en especial, en la manera como los sujetos establecen nuevas relaciones desde sus prácticas familiares cotidianas, desde los ecos de la cultura en que están inmersos, desde los contextos educativos y laborales en los que se tejen nuevas relaciones y 


\section{Talea Clara Inés Giraldo Naranjo}

significados, y aparecen así otros imaginarios y percepciones desde los cuales surgen y toman fuerza categorías como la exclusión, el rechazo, la segregación, las desigualdades, la marginalidad, la competitividad y las conductas individualistas. Hoy son éstas las nuevas rutas y condiciones que se impregnan en las conciencias de las personas y que representan a una gran mayoría de los individuos que hacen parte de la sociedad.

Para finalizar este escrito, es importante denotar que en la actualidad estamos transitando por nuevos caminos donde imperan pensamientos centrados en el bienestar individual; espacios donde es más relevante tener que ser; escenarios donde prima una filosofía centrada en la consigna "sálvese quien pueda"; ¡y quién lo creyera!: son todas estas nuevas informaciones, circunstancias, situaciones y experiencias las que están contribuyendo a la reconfiguración de lo subjetivo y, por ende, de lo humano, o, definitivamente, al surgimiento de la deshumanización de todos.

Hoy, más que nunca, se requiere un sujeto capaz de encontrarse consigo mismo y de construir nuevas realidades y prácticas cotidianas, desde actos propositivos y propios que resalten la construcción y edificación de paradigmas de respeto y dignificación, donde lo humano sea el centro y el eje transversal en la construcción de nuevas subjetividades y realidades.

\section{Referencias}

Bajtín, M. (1982). Estética de la creación verbal. México D. F.: Siglo XXI.

Berger, P. L. (2001). La sociedad como realidad objetiva. Buenos Aires: Amorrortu.

Ricoeur, P. (2006). Caminos del reconocimiento. Buenos Aires: Fondo de CulturaEconómica.

Rizo, M. (2005). La intersubjetividad como eje conceptual para pensar la relaciónentre comunicación, subjetividad y ciudad. Revista electrónica Razón y Palabra, 47. Recuperado dehttp://www. razonypalabra.org.mx/anteriores/n47/ mrizo.html

Ruiz Martín del Campo, E. (1988). Subjetividad femenina. Red de revistas científicas de América Latina, 5 (13), 143160.

Schütz, A. \& Luckmann, T. (1973). Las estructuras del mundo de la vida. Buenos Aires: Amorrortu.

Vargas Guillén, G. (2007). Formación y subjetividad. Bogotá: Universidad Pedagógica. 